\section{Commentary: Open or VATS? Roll up your sleeve}

\author{
Taryne Imai, $\mathrm{MD},{ }^{\mathrm{a}}$ and Benny Weksler, $\mathrm{MD}^{\mathrm{b}}$
}

Sleeve lobectomy is a valid alternative to pneumonectomy for centrally located, non-small-cell lung cancers, offering comparable oncologic outcomes and preserves the lung parenchyma. ${ }^{1,2}$ Traditionally, the technical demands of sleeve lobectomy have necessitated thoracotomy; however, as surgeons have become more skilled with minimally invasive techniques such as video-assisted thoracoscopic surgery (VATS) and robotic surgery, many have applied minimally invasive techniques beyond routine lobectomy and have extended the surgical approach to sleeve resections. ${ }^{3,4}$

Previous publications on minimally invasive sleeve resection were descriptive case series, focusing on surgical technique and outcomes. ${ }^{3,4}$ These studies demonstrated the feasibility of the VATS approach for sleeve lobectomy. More recent publications have compared VATS sleeve resections with the standard thoracotomy approach and have demonstrated comparable complication rates and overall survival. ${ }^{5}$ In addition, the VATS approach offered less blood loss, decreased chest tube duration, and shorter postoperative hospital stay. ${ }^{6}$ Therefore, VATS sleeve lobectomies have been proven safe, have oncologic outcomes equivalent to those of open sleeve resections, and offer benefits during the postoperative period.

In this issue of the Journal, Xie and colleagues ${ }^{7}$ share their results of a propensity-matched analysis comparing the outcomes of sleeve lobectomy performed using VATS with sleeve lobectomy performed via thoracotomy. A total of 363 patients (112 with VATS, 251 with thoracotomy) underwent sleeve resection. After a 2:1 propensity-score matching, the analysis included 116 thoracotomy cases and 72 VATS cases (43 with uniportal VATS, 29 with standard multiportal VATS). The VATS and thoracotomy groups demonstrated

\footnotetext{
From the ${ }^{\mathrm{a}}$ Division of Thoracic Surgery, Department of Surgery, Cedar Sinai Medical Center, Los Angeles, Calif and the ${ }^{\mathrm{b}}$ Division of Thoracic and Esophageal Surgery, Department of Thoracic and Cardiovascular Surgery, Allegheny General Hospital, Pittsburgh, Pa.

Disclosure: Benny Weksler, MD, is a proctor for Intuitive Surgery and serves on the speakers bureau for AstraZeneca.

Received for publication March 14, 2020; revisions received March 14, 2020; accepted for publication March 16, 2020; available ahead of print April 6, 2020.

Address for reprints: Benny Weksler, MD, Division of Thoracic and Esophageal Surgery, Department of Thoracic and Cardiovascular Surgery, Allegheny General Hospital, 320 E North Ave, 14th Floor, South Tower, Pittsburgh, PA 15212 (E-mail: benny.weksler@ahn.org).

J Thorac Cardiovasc Surg 2021;161:414-5

$0022-5223 / \$ 36.00$

Copyright (c) 2020 by The American Association for Thoracic Surgery

https://doi.org/10.1016/j.jtcvs.2020.03.109
}

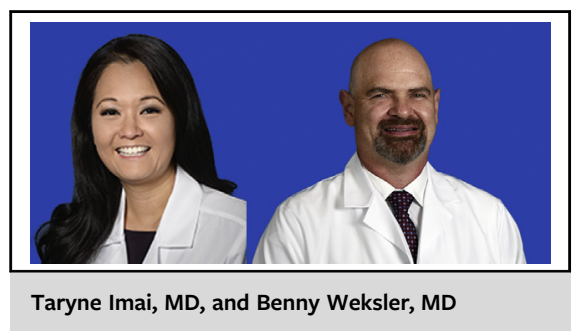

CENTRAL MESSAGE
A large, propensity-matched
analysis of sleeve lobectomies
strengthens consideration of
minimally invasive approaches
for sleeve resection instead of
thoracotomy and validates the
uniportal option.

similar staging distributions, operative times, lymph node yield, and 30- and 90-day mortality. The patients who underwent VATS sleeve lobectomy had better perioperative outcomes than patients who underwent open sleeve resection, with less intraoperative blood loss, shorter intensive care unit stay, decreased chest tube duration, and shorter postoperative hospital stay. The incidence of postoperative complications was $9.0 \%$ in the matched cohort, and the most common complication in both groups was prolonged air leak. In addition, there was no difference in disease progression between the 2 groups, and the groups had a similar proportion of patients who received adjuvant therapy. The 2 groups had a similar estimated 3-year overall survival (VATS, $68.8 \%$; thoracotomy, $65.9 \% ; P=.24$ ) and estimated 3-year disease-free survival (VATS, $60.8 \%$; thoracotomy, $53.9 \% ; P=.20$ ). The authors conclude that the minimally invasive approach to sleeve lobectomy upholds the proven postoperative benefits of performing lung resection using VATS without compromising surgical or oncologic outcomes.

Although the study by Xie and colleagues demonstrates similar findings as reported in previous publications, their study is one of the largest series of minimally invasive sleeve lobectomies to date and thus should strengthen the support for considering VATS as a standard approach to sleeve resection. Another unique aspect of the study is its incorporation of the uniportal technique within the VATS group. Because the majority of patients who underwent minimally invasive sleeve resection underwent uniportal VATS, the implication may be made that uniportal VATS sleeve lobectomy yields surgical and oncologic outcomes comparable with those of the current standard of care, thoracotomy. 
Despite the encouraging results highlighting the feasibility of VATS sleeve lobectomy presented here, the generalizability of this study to VATS sleeve lobectomies performed at other centers remains in question. Minimally invasive approaches to sleeve lobectomies are often described and are generally considered options that should be performed at an experienced, high-volume, academic center. Many centers have a limited volume of patients requiring sleeve lobectomy and/or surgeons that may deem large central tumors unresectable and thus direct patients to definitive therapies with no attempt at resection. In addition, many surgeons who have adopted VATS lobectomy as their standard practice will opt to perform thoracotomy when tasked with a sleeve resection, owing to their limited experience performing advanced resections with VATS, the increased technical demands of bronchoplastic work, or the greater potential for complications. Therefore, although the study by Xie and colleagues is a worthwhile addition to the growing body of literature confirming the feasibility of VATS sleeve lobectomy, realistically, minimally invasive approaches for sleeve resections likely will not be adopted as the standard of care in the near future and will remain an option at select centers.

\section{References}

1. Deslauriers J, Gregoire J, Jacques LF, Piraux M, Guojin L, Lacasse Y. Sleeve lobectomy versus pneumonectomy for lung cancer: a comparative analysis of survival and sites of recurrences. Ann Thorac Surg. 2004;77:1152-6; discussion 1156.

2. Ludwig C, Stoelben E, Olschewski M, Hasse J. Comparison of morbidity, 30-day mortality, and long-term survival after pneumonectomy and sleeve lobectomy for non-small-cell lung carcinoma. Ann Thorac Surg. 2005;79:968-73.

3. Caso R, Watson TJ, Khaitan PG, Marshall MB. Outcomes of minimally invasive sleeve resection. J Thorac Dis. 2018;10:6653-9.

4. Mahtabifard A, Fuller CB, McKenna RJ Jr. Video-assisted thoracic surgery sleeve lobectomy: a case series. Ann Thorac Surg. 2008;85:S729-32.

5. Zhou S, Pei G, Han Y, Yu D, Song X, Li Y, et al. Sleeve lobectomy by videoassisted thoracic surgery versus thoracotomy for non-small-cell lung cancer. $J$ Cardiothorac Surg. 2015;10:116.

6. Gao HJ, Jiang ZH, Gong L, Ma K, Ren P, Yu ZT, et al. Video-assisted vs thoracotomy sleeve lobectomy for lung cancer: a propensity-matched analysis. Ann Thorac Surg. 2019;108:1072-9.

7. Xie D, Deng J, Gonzalez-Rivas D, Zhu Y, Jiang L, Jiang G, et al. Comparison of video-assisted thoracoscopic surgery with thoracotomy in bronchial sleeve lobectomy for centrally located non-small-cell lung cancer. J Thorac Cardiovasc Surg. 2021;161:403-13.e2.
See Article page 403 .

\section{Commentary: Minimally invasive sleeve lobectomy: Time to roll up our "sleeves" and learn something new?}

\author{
Neel P. Chudgar, MD, and Matthew J. Bott, MD
}

Sleeve lobectomy has long been recognized as a reliable procedure for the management of centrally located lung cancers. ${ }^{1}$ Several studies have demonstrated long-term survival with this lung-preserving operation comparable with that of pneumonectomy. ${ }^{2,3}$ Although bronchial

\footnotetext{
From the Thoracic Service, Department of Surgery, Memorial Sloan Kettering Cancer Center, New York, NY.

Disclosures: Authors have nothing to disclose with regard to commercial support.

Received for publication Feb 28, 2020; accepted for publication Feb 28, 2020; available ahead of print March 19, 2020.

Address for reprints: Matthew J. Bott, MD, Thoracic Service, Department of Surgery, 1275 York Ave, Memorial Sloan Kettering Cancer Center, New York, NY 10065 (E-mail: bottm@mskcc.org).

J Thorac Cardiovasc Surg 2021;161:415-6 $0022-5223 / \$ 36.00$

Copyright (c) 2020 Published by Elsevier Inc. on behalf of The American Association for Thoracic Surgery

https://doi.org/10.1016/j.jtcvs.2020.02.121
}

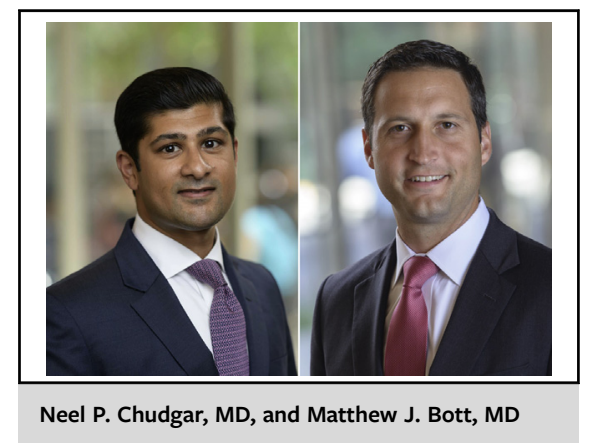

CENTRAL MESSAGE

Thoracoscopic sleeve lobectomy

can be performed with compara-

ble morbidity, mortality, and sur-

vival to thoracotomy in

appropriately selected patients

when performed by experienced

surgeons.

reconstruction adds to the level of complexity, increased experience with sleeve lobectomy over time has naturally led to the incorporation of techniques of minimally invasive 